Jurnal MAKSIPRENEUR, Vol. V, No. 1, Desember 2015, hal. 75 - 92

\title{
ANALISIS FAKTOR-FAKTOR YANG MEMPENGARUHI PERILAKU KONSUMEN WARUNG LESEHAN DI KOTA YOGYAKARTA
}

Drs. Jemadi. MM (jemadi08@yahoo.com)

Fakultas Ekonomi, Universitas Proklamasi 45 Yogyakarta

Drs. Bambang Sugeng Dwiyanto, MM (bsugengd@yahoo.co.id)

Fakultas Ekonomi, Universitas Proklamasi 45 Yogyakarta

ABSTRACT. Research with the title: "Analysis of Factors Affecting Consumer Behavior Warung Lesehan in Yogyakarta", aims to investigate the characteristics of consumers shop Lesbian and to determine the factors that influence consumer behavior lesehan food, when seen from the income factor, location, service, hygiene, recreation, price and location or a shop selling lesehan, as well as to determine the most dominant influence on consumer behavior lesehan food. In this study the factors thought to influence consumer behavior is limited in six factors: income, service, hygiene, recreation, price and location / place to sell. Analyzers in this study consisted of two kinds: First analysis of descriptive is to kengetahui consumer characteristics seen from the gender (male, female), national origin (DIY, outdoor DIY), age (less than 20 years old, 20-30 years, 30-40 years, 40-50 years above 50 years), education (junior high, high school, PT), employment (Private employees, civil servants, Self Employed, Military / Police, Student), obtained the following results:

a. Based on the sex of the respondents, 90 respondents or $60 \%$ are female, and male gender, the number of 60 respondents or $40 \%$.

b. Based on the age of respondents, mostly aged 20-30 years is 66 respondents (44\%), second younger than 20 years as many as 30 respondents (20\%), were the least respondents aged greater than 50 years is 14 or 9,3\% .

c. By level of education, most high school education is 72 respondents or $48 \%$ then higher education as much as 38 or $25.3 \%$, while the least no school / SD by 10 or $6.7 \%$

d. The work is based on a student / students as many as 68 respondents, or 45.3 $\%$, followed by the order to two civil servants as much as 34 or $22.7 \%$ and the smallest farmers as much as 6 respondents or only $4 \%$.

e. By region of origin, from the outside DIY as many as 104 or $69.3 \%$ while the DIY as much as 46 or $30.7 \%$.

Medium to find out if there is a significant relationship between the factors that influence consumer behavior (itensitas purchases) using Chi Square. From 150 
responden as samples, taken from 10 stalls lesehan with acidental sampling method, the results are as follows:

a. $X^{2}$ is based on the analysis of all factors (revenue, location, taste, hygiene, recreation/ entertainment and price) of all effect / no relationship to consumer behavior Lesbian stalls in the city of Yogyakarta.

b. Factors most powerful influence on consumer behavior is a recreation/entertainment, shows that the stall lesehan seen not merely a place to eat but has become an arena / place amuse yourself / recreation for consumers, while the population is all consumers shop cross-legged in the city of Yogyakarta.

This research is expected to generate outputs in the form of Scientific Publication in the Journal of Air ISSN and local seminars.

Key words: Characteristics of consumers, Consumer behavior, Warung lesehan

\section{PENDAHULUAN}

A. Latar Belakang dan permasalahan Penelitian

Usaha pedagang lesehan pada masa sekarang ini sudah banyak dijumpai di berbagai kota, tidak ketinggalan di kota Yogyakarta yang dikenal sebagai kota budaya, dan pendidikan. Pedagang lesehan di kota Yogyakarta mulanya dimulai di kawasan Malioboro yang merupakan jantung kota Yogyakarta. Malioboro dibangun tahun 1946 merupakan tempat-tempat yang begitu kompleks dengan berbagai macam kegiatan baik bisnis, hiburan dan pedagang kaki lima sampai tempat belanja yang modern dapat dijumpai disitu. Hal tersebut dapat menimbulkan daya tarik bagi orang-orang yang berkunjung ke Yogyakarta baik dari wisatawan manca negara maupun wisatawan nusantara untuk singgah di Malioboro. Karena kehidupan di malioboro hampir tidak pernah berhenti selama 24 jam maka menarik bagi sebagian orang untuk melayani kuliner yang murah, bersih, siap saji, dan santai yaitu dengan cara lesehan. Peluang inilah yang dimanfaatkan oleh para pedagang untuk menjual makanan yang merupakan ciri khas hidangan Yogyakarta dan banyak digemari atau ingin dicoba oleh orang-orang yang berkunjung ke Malioboro untuk menikmatinya. Seiring dengan meningkatnya pengunjung ke Yogyakarta maka mulai tumbuhlah warung-warung lesehan di berbagai tempat di kota Yogyakarta. Tumbuh berkembangnya warung lesehan tidak terlepas dari meningkatnya daya beli masyarakat.Robert Ferber mengatakan 
bahwa sebagai ciri-ciri khas yang menentukan seorang konsumen berkenaan dengan perilaku berbelanja adalah pendapatan. (Philip Kotler dan Keith Cox, 1984)

Dengan melihat peluang di atas langkah awal yang ditempuh oleh pengusaha adalah menentukan lokasi tempat usahanya.Faktor lokasi merupakan hal yang penting bagi suatu usaha jasa. Sinubo Sinukarto mengemukakan bahwa ciri umum lokasi yang baik untuk usaha jasa makanan misalnya bertempat dekat dengan konsumen, dan berikan pelayanan yang sebaik-baiknya kepada konsumen agar konsumen tak lari ke orang lain dan permintaan tetap tinggi (Kafi Kurnia, 1991)

Namun perlu diketahui bahwa pelayanan saja tidak cukup untuk menjaring konsumen tetapi perlu juga memperhatikan selera. Sejak lahir masing-masing orang punya selera sendiri, selera itu dipelajari oleh simbol-simbol budaya dan ketersediaan bahan baku disertai lingkungan hidup kita. Namun benarkah selera tak mungkin diciptakan?. Dalam manajemen pemasaran kita mengenal doktrin consumer's taste yang merupakan bagian dari perilaku konsumen : buatlah apa yang diinginkan konsumen bukan apa yang kamu ingin dan bisa membuatnya artinya ikutilah pasar. Parlin berpendapat jualah makanan yang kebetulan saat itu sedang mengundang seleranya (Parlin, 1987)

Masalah kebersihan juga menjadi faktor penting yang selahi diparhatikan dalam memulai bisnis makanan. Seperti pendapat yang dikemukakan oleh Anni Iwasaki bahwa, orang Jepang umumnya sangat bersih, mereka tidak bisa makan di restoran-restoran yang apa adanya. Misalnya taplak meja tidak disetrika atau mejanya dekil, pelayanan tidak rapi, menyuguhkan makanan sambil berbicara atau tertawa, piring dan sendok harus tampak baru dan bersih (Anni Iwasaki, 2007).

Di lain pihak Ki Mangun Atmojo berpendapat para pengunjung lesehan juga banyak yang menaruh minat cukup besar terhadap rekreasi/hiburan, terbukti masih seringnya para pengamen dicarter oleh salah satu pengunjung (Ki Mangun Atmojo 1990). Selanjutnya faktor yang tidak kalah pentingnya yaitu harga.Apabila konsumen melakukan pembelian, faktor harga merupakan faktor yang cukup mempengaruhi pertimbangan konsumen melakukan pembelian.Hal ini sejalan dengan pendapat Chairul Hidayat bahwa restoran tidak semata berpegang pada 
mutu produk, pelayanan dan kebersihan, tetapi juga memperhatikan masalah harga (Chairul Hidayat, 1987).

Berdasarkan latar belakang tersebut dapat dirumuskan permasalahan sebagai berikut: Di dalam penelitian sebagai variabel yang mempengaruhi perilaku konsumen adalah mencakup : Apakah ada hubungan atau pengaruh antara faktorfaktor pendapatan, lokasi, pelayanan, selera, kebersihan, rekreasi dan harga dengan perilaku konsumen warung lesehan di Kota Yogyakarta?

B. Tujuan penelitian.

Penelitian ini bertujuan untuk mengetahui Karakteristikkonsumen warung lesehan dan dan faktor yang paling dominan mempengaruhi perilaku konsumen warung lesehan di kota Yogyakarta.

\section{TINJAUAN PUSTAKA}

\section{A. Pengertian Perilaku Konsumen}

Mempelajari perilaku konsumen tidak hanya mempelajari apa yang dibeli atau dikonsumsi, tetapi juga dimana, bagaimana kebiasaannya dan dalam kondisi macam apa barang-barang dan jasa-jasa, dibeli sehingga perusahaan akan mudah mencapai sasaran dalam memasarkan produknya.Perilaku konsumen (consumer behaviour) dapat didefinisikan sebagai sebagai kegiatan-kegiatan individu yang secara langsung terlibat dalam mendapatkan dan mempergunakan barang-barang dan jasajasa termasuk di dalamnya proses pengambilan keputusan pada persiapan dan penentuan kegiatan-kegiatan tersebut (Basu Swastha DH, T. Hani Handoko, 2002).Definisi perilaku konsumen yang lain, dikemukakan oleh A.A. Anwar Prabu Mangkunegoro sebagai berikut :Perilaku konsumen adalah merupakan kegiatankegiatan individu yang secara langsung terlibat dalam mendapatkan dan mempergunakan barang-barang dan jasa-jasa termasuk di dalamnya proses pengambilan keputusan dan persiapan dan peentuan kegiatan. Definisi perilaku konsumen yang lain dikemukakan oleh A.A. Anwar Prabu Mangkunegoro, Perilaku konsumen dapat didefinisikan sebagai proses pengambilan keputusan dan aktivitas individu secara fisik yang dilihat dalam mengevaluasi, memperoleh, menggunakan atau dapat mempergunakan barang-barang dan jasa (A.A. Anwar Prabu 
Mangkunegoro, 1988).Kedua definisi tentang perilaku konsumen tersebut mengandung beberapa aspek pengertian bahwa : (1) Perilaku konsumen merupakan proses pengambilan keputusan. (2). Perilaku konsumenmerupakan kegiatan fisik dan mental untuk mendapatkan danmenggunakan barang dan atau jasa ekonomis. Setiap individu memiliki perilaku yagn berbeda dalam usaha pemenuhan kebutuhan dan keinginannya.Hal ini disebabkan adanya perbedaan faktor-faktor yang mempengaruhi konsumen dalam pengambilan keputusan untuk pembelian produk.Faktor-faktor tersebut dapat berasal dari luar dan dari dalam individu konsumen.Faktor-faktor tersebut menurut (Basu Swastha DH, T. Hani Handoko, 2002) adalah:

\section{Faktor Kebudayaan}

Faktor kebudayaan memiliki pengaruh terhadap perilaku konsumen karena budaya merupakan kumpulan nilai-nilai dasar, persepsi keinginan dan tingkah laku yang dipelajari oleh seseorang anggota masyarakat dan lembaga penting lainnya. Dalam budaya terdapat sub-budaya, yang merupakan bagian dari kebudayaan. Sub-budaya adalah sekelompok orang yang mempunyai sistem nilai sama berdasarkan pengalaman hidup dan situasi diantaranya nasionalitas, agama, kelompok ras, wilayah geografi .

\section{Faktor Sosial}

Sebagai tambahan atas faktor kebudayaan, perilaku seorang konsumen dipengaruhi oleh faktor-faktor sosial seperti kelompok acuan, keluarga serta peranan dan status, yang dimaksud dengan: Kelompok acuan adalah kelompok-kelompok yang memberikan pengaruh langsung maupun tidak langsung terhadap sikap dan perilaku seseorang. Keluarga adalah tempat dimana individu pertama kali mulai tumbuh dan bersosialisasi. Anggota keluarga membentuk referensi yang paling berpengaruh dalam membentuk perilaku konsumen. Peranan dan status adalah kedudukan seseorang dalam setiap kelompok. Orang seringkali memilih produk yang dapat menunjukkan statusnya dalam masyarakat. 


\section{Faktor Pribadi}

Keputusan pembeli juga dipengaruhi oleh karakteristik pribadi, karakteristik pribadi yang terdiri usia, pekerjaan, keadaan ekonomi, gaya hidup dan kepribadian.

\section{Faktor Psikologi}

Pilihan pembelian seseorang dipengaruhi oleh empat faktor psikologi utama yaitu : Motivasi adalah dorongan dari dalam diri setiap individu yang mengarahkan seseorang untuk mencapai apa yang diinginkan. Kebutuhan psikologis muncul dari kebutuhan akan pengakuan, penghargaan atau rasa memiliki. Kebutuhan berubah menjadi motif kalau merangsang sampai tingkat intensitas yang mencukupi. Motif adalah kebutuhan yang cukup mendorong seseorang untuk bertindak. Persepsi adalah proses yang dilalui orang dalam memilih, mengorganisasikan dan mengintegrasikan masukanmasukan informasi untuk menciptakan gambaran dunia yang memiliki arti. Belajar adalah perubahan dalam perilaku seseorang individu yang bersumber dari pengalaman. Pentingnya praktik dan teori pengetahuan bagi pemasar adalah mereka dapat membentuk permintaan akan suatu produk dengan menghubungkan dengan dorongan yang kuat, menggunakan petunjuk yang membangkitkan motivasi dan memberikan pembenaran positif. Kepercayaan dan sikap, kepercayaan adalah pemikiran diskriptif yang dianut seseorang tentang suatu hal sedangkan sikap adalah evaluasi, perasaan emosional, dan kecenderungan tindakan yang menguntungkan atau tidak menguntungkan dan bertahan lama dari seseorang terhadap beberapa objek atau gagasan.

\section{B. Pengertian Warung Lesehan}

Lesehan adalah suatu budaya dalam hal memperjualbelikan makanan atau sesuatu barang sembari duduk di tikar/lantai.Makanan atau barang yang diperjualbelikan turut digelar pada saat lesehan sehingga pengunjung bisa melihat dan memilihnya dengan santai (http://id.wikipedia.org/wiki/lesehan).Budaya Lesehan yang sangat terkenal di Indonesia adalah di daerah Yogyakarta dan hal ini 
menjadi salah satu daya tarik tersendiri bagi mahasiswa/pelajar, wisatawan, baik dari dalam maupun luar negeri serta masyarakat Yogyakarta pada umumnya.

Warung lesehan ini tidaklah seperti warung-warung makan biasa yang membutuhkan perlengkapan serba modern dan formal.Warung lesehan adalah warung yang menggunakan perlengkapan yang sangat sederhana untuk melakukan kegiatannya dengan tikar sebagai tempat duduk pembeli (konsumen) dan meja kecil yang tingginya tidak lebih dari 40 sentimeter menghiasai suasana yang lebih santai dibanding dengan warung-warung makan biasa pada umumnya.Warung lesehan ini mempunyai ciri khas yang tersendiri, kegiatannya yaitu dilakukan pada menjelang malam hari dan kegiatannyapun tidak terorganisir dengan baik serta tidak memerlukan pendidikan yang formal (hanya berdasarkan pengalaman saja dan tehnologi yang digunakanpun sangat sederhana).Dalam melakukan kegiatannya biasanya dilakukan hanya anggota keluarga saja dan kalaupun memakai bantuan dari luar itu sangat sedikit sekali tidak lebih dari enam orang serta modalnyapun hanya bersumber pada modal sendiri.Warung lesehan mulai dikenal dan digemari masyarakat pada sekitar tahun 1972. Pada awalnya daerah kawasan warung lesehan merupakan tempat berkumpulnya seniman-seniman dalam mencari inspirasi atau untuk tempat bertukar pikiran sesama seniman.Jumlah warung lesehan pada awalnya jumlahnya tidak terlalu banyak dan menu yang ditawarkan hanya masakan khas Yogyakarta yaitu Gudeg.Lokasi warung lesehan banyak menempati di sepanjang jalan protokol, seperti Jl. Malioboro, Jalan Ahmad Yani, Jalan Mangkubumi,Jalan Perwakilan dan sepanjang jalan Solo.Banyak warung lesehan digelar di sepanjang jalan tersebut, ketika menjelang malam wajah dijalan protokol tersebut berubah, yang tadinya disibukkan oleh lalu lalang orang yang berbelanja.Setelah menjelang malam berubah menjadi suasana santai dengan dibukanya warung-warung lesehan di sepanjang jalan tersebut. Perubahan ini biasanya terjadi setelah toko-toko tutup dan pedagang kaki lima pulang, tepatnya pukul 21.00 WIB. Dengan dibukanya warung lesehan ini banyak para pengunjung yang makan, minum dengan santainya sambil menikmati udara malam yang dingin dengan bebas, dengan santainya sambil menikmati udara malam yang dingin 
dengan bebas, dengan berbagai menu masakan yang ditawarkan, seperti ayam goreng, gudeg, serta beraneka minuman seperti kopi, susu, jahe, teh, jeruk dan sebagainya yang semua makanan dan minuman tersebut dapat diperoleh di warung lesehan. Keadaan ini juga dimanfaatkan para seniman muda yang berpotensi untuk mengembangkan keahlian mereka.Mereka ada yang berkumpul untuk mencari sumber inspirasi dan ada yang mengembangkan keahliannya dengan mengamen untuk menghibur orang yang sedang menikmati masakan warung lesehan dan ada juga melukis wajah para pengunjung.

\section{Faktor-Faktor Yang Mempengaruhi Perilaku Konsumen.}

Dalam usaha warung lesehan perlu memperhatikan banyak faktor, yang tentunya juga sangat dibutuhkan atau diperhatikan oleh konsumen. Diantara faktorfaktor yang harus diperhatikan adalah: pendapatan, lokasi, pelayanan, selera, kebersihan, rekreasi/hiburan dan harga. Pendapatan sangat penting karena merupakan kemampuan daya beli dari masyarakat, lokasi yang mudah dijangkau dengan memerikan rasa aman bagi konsumen sangat dibutuhkan. Pelayanan dalam melayani konsumen harus diperhatikan karena usaha warung lesehan ini termasuk usaha jasa. Selera konsumen sedapat mungkin dipenuhi dengan berupaya menyajikan menu yang dapat disenangi oleh konsumen sehingga dapat menggugah selera konsumen. Kebersihan harus diutamakan karena usaha jasa makanan harus dapat menjamin bahwa makanan yang di jajakan bersih/sehat. Rekreasi, seiring dengan maraknya berjualan warung lesehan maka konsemen yang datang ke warung lesehan tersebut tidak hanya semata-mata makan tetapi mencari hiburan dengan kongkow-kongkow dan berlama lama sambil menikmati malamnya kota Yogyakarta. Harga adalah nlai yang diperoleh atas jasa yang doberikan oleh penjual warung lesehan, harga ini harus seimbang dengan apa yang dapat dinikmasi oleh konsumen. 
D. Kerangka Pikir

Kerangka pikir dalam penelitian ini adalah sebagaimana gambar 1 berikut:

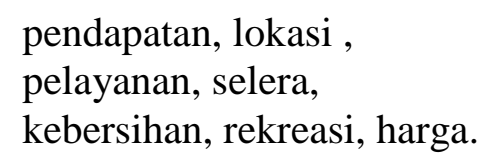

Gambar 1. Kerangka pikir

\section{METODE PENELITIAN}

A. Variabel dan Definisi Operasional

Variabel Independen adalah variabel yang mepengaruhi perilaku konsumen untuk makan di warung lesehan meliputi : Pendapatan, lokasi, pelayanan, selera, kebersihan, rekreasi/hiburan, harga.

1. Pendapatan Konsumen

Seluruh pendapatan dalamrupiah diterima oleh seseorang dalam setiap bulan, bagi yang sudah bekerja sedangkan bagi yang belum bekerja besarnya kiriman orang tua yang diterima rata-rata setiap bulan.

2. Lokasi

Tempat berjualan warung lesehan yang dianggap strategis sehingga konsumen dapat menjangkau tempat makan dengan mudah, aman dan tempat parkir yang luas.

3. Pelayanan

Perbuatan yang ditunjukkan oleh pedagang atau karyawannya sendiri secara langsung mencakup sikap ramah, cekatan, sopan, tepat waktu saji.

4. Selera

Keinginan yang dimiliki konsumen untuk makan di warung lesehan yang

didorong oleh cita rasa, keragaman menu masakan, menarik, unik karena warung lesehan memiliki ciri khas khusus tempat duduk konsumen di tikar atau karpet dengan santai sambil menikmati menu yang ditawarkan.

5. Kebersihan 
Keadaan sarana dan prasarana serta lingkungan yang bersih, sehat dan tidak berbau.

6. Rekreasi/hiburan

Keadaan dimana terdapat suasana yang klasik dan unik dengan suasana santai sambil menikmati lalu lalang berbagai kendaraan dan berbagai musik pilihan /pengamen dari yang tradisional sampai musik modern.

7. Harga

Persepsi konsumen terhadap harga makanan di lesehan dari menu masakan yang ditawarkan.

Sedangkan variabel dependen adalah perilaku konsumen, yang ditunjukan oleh tingkat itensitas pembelian atau tingkat keseringan melakukan pembelian di warung lesehan.

\section{B. Populasi dan Sampel}

Populasi dalam penelitian ini adalah semua orang yang makan di segala macam warung lesehan di Kota Yogyakarta. Karena jumlah populasi sangat besar dan tidak diketahui jumlahnya maka metode pengambilan sampel dilakukan dengan cara "Accidental Sampling". Accidental Sampling adalah sampel yang diambil dari siapa saja yang kebetulan ada.Metode Accidental Samplingini digunakan karena populasi yang tidak jelas(Sugiyono, 2004). Cara pengambilan sampel dalam metode ini yaitu menjadikan Sampel orang yang secara kebetulan ditemui ditempat penelitiandan orang yang ditemui itu dijadikan sampel (responden). Untuk menetukan jumlah sampel dari populasi yang tidak diketahui jumlahnya tergantung dari besarnya tingkat signifikansi dan kesalahan (error). Dalam hal ini menggunakan tingkat signifikansi $(\alpha)=5 \%$ dan tingkat kesalahan (error) yang terjadi maksimal 10\% maka banyaknya sampel yang diambil menggunakan rumus $\mathrm{N}=\mathrm{Z} / 4 \mathrm{MOE}^{2}$ dimana $\mathrm{N}=$ jumlah sampel, $\mathrm{Z}=$ tingkat significane, $\mathrm{MOE}=$ Margin Off Error maksimum (tingkat kesalahan maksimum yang dapat ditoleransi). Berdasarkan rumus tersebut maka besarnya $\mathrm{N}$ (sampel) adalah $1,96^{2} / 4(10 \%)^{2}=97$ merupakan sampel minimal yang diambil agar dapat mewakili populasi yang 
diteliti. Dalam penelitian ini sampel yang diambil 150 responden sudah melebihi dari syarat minimal 97 responden.

C. Metode Pengumpulan Data

1). Data Primer

Data diperoleh melalui wawancara dengan konsumen dan dipandu dengan kuisioner, atas variabel yang mempengaruhi perilaku konsumen yaitu: Pendapatan, Lokasi, Pelayanan, Selera, Kebersihan, Rekreasi/hiburan, Harga

2). Data Sekunder

Data yang diperoleh dengan terlebih dahulu dikumpulkan dan dilaporkan oleh orang lain atau data yang sudah ada yang berasal dari Perkumpulan Pedagang Kakilima yang membawahi para pedagang lesehan di Kota Yogyakarta. Data sekunder yang dibutuhkan dalam penelitian ini adalah data yang menunjuk kan tentang gambaran umum warung lesehan di Kota Yogyakarta.

D. Analisis Data

Metode Analisis yang akan digunakan dalam penelitian ini adalah :

1. Analisis Kualitatif

Metode analisis kualitatif adalah analisis yang dilakukan dengan perbandingan dan penafsiran jawaban kuesioner. Hasil perbandingan dan penafsiran jawaban tersebut kemudian diambil suatu kesimpulan. Analisis kualitatif dilakukan terhadap suatu penelitian untuk melakukan argumentasi dan logika. Medode analisis kualitatif salah satunya dianalisis dengan cara membuat tabel hasil perbandingan jawaban responden sehingga nantinya didapat perbandingan dan penafsiran berdasarkan jawaban kuisioner tersebut serta peneliti mendiskripsikan keadaan konsumen warung lesehan berupa karakteristik konsumen yang terdiri jenis kelamin, usia, pendidikan, pekerjaan, asal daerah.

2. Analisis Kuantitatif. 
Metode ini menggunakan perhitungan statistik atau matematika. Hasil analisis diperoleh dari informasi atau data yang digunakan untuk melakukan uji tingkat kepuasan. Untuk analisa kuantitatif dalam penelitian ini menggunakan analisa Chi Square (Kai Kuadrat) yaitu analisis yang digunakan untuk mengetahui apakah apakah ada hubungan yang signifikan antara faktor-faktor yang mempengaruhi perilaku konsumen terhadap intensitas pembelian/tingkat keseringan melakukan pembelian di warung lesehan.

Adapun rumus kai kuadrat adalah: (Djarwanto PS dan Pangestu Subagyo,2007)

$$
\chi^{2}=\sum_{i=1}^{n} \frac{\left(F_{0}-F h\right)^{2}}{F h}
$$

Keterangan

$\chi^{2} \quad$ : adalah nilai kai kuadrat $\left(\mathrm{X}^{2}\right.$ hitung)

Fh $\quad$ : adalah frekwensi yang diharapkan dari sampel sebagai

Fo : adalah frekwensi hasil observasi

Untuk memperoleh niali Fh digunakan rumus:

$$
\mathrm{Fh}=\frac{(\text { total baris) } x \text { (total kolom })}{\text { total sampel }}
$$

Apabila $\chi^{2}$ hitung lebih besar dari $\chi^{2}$ tebel maka maka antara varibel dependen dan variable independen terdapat hubungan/pengaruh, dan sebaliknya apabila $\chi^{2}$ hitung lebih kecil dari $\chi^{2}$ tabel maka antara variable dependen dan variable independen tidak ada hubungan/pengaruh, sedang untuk mengetahui derajat keeratan hubungan kedua variable penelitian dengan membandingkan besarnya koefisien kontigengsi (C) dengan koefisienkontigengsi maximum (C maks)

Adapun rumus kedua koefisien tersebut adalah: 


$$
\mathrm{C}=\sqrt{\frac{\chi^{2}}{\mathrm{~N}+\chi^{2}}} \quad C_{\text {maks }}=\sqrt{\frac{\boldsymbol{m}-\mathbf{1}}{\boldsymbol{m}}}
$$

\section{Dimana :}

$\mathrm{m}=$ Adalah jumlah yang paling kecil antara jumlah baris jumlah kolom $\mathrm{N}=$ Adalah jumlah sampel

Semakin dekat antara koefisien kontingensi (C) dengan koefisien kontingensi maksimum (C maks) maka derajad hubungan ke dua variabel semakin erat dan sebaliknya, apabila koefisien kontingensi (C) dengan koefisien kontingensi maksimum (C maks)semakin menjauh maka derajad hubungan ke dua variabel semakin lemah.

E. Uji Validitas dan Reliabilitas

1). Uji Validitas

Validitas menurut Suharsimi Arikunto (2002) adalah suatu ukuran yang menunjukan tingkat kesahihan suatu instrumen penelitian. Suatu instrumen penelitian yang valid mempunyai validitas yang tinggi, sebaliknya instrumen yang kurang valid berarti memiliki validitas yang rendah.

Pengujian menggunakan uji dua sisi dengan taraf signifikansi 0,05 dengan kriteria pengujian sebagai berikut:

- Jika $r$ hitung $\geq \mathrm{r}$ tabel (uji 2 sisi dengan sig. 0,05) maka instrumen atau item-item pertanyaan berkorelasi signifikan terhadap skor total ( dinyatakan valid)

- Jika $r$ hitung $<r$ tabel (uji 2 sisi dengan sig. 0,05) maka instrumen atau itemitem pertanyaan tidak berkorelasi signifikan terhadap skor total (dinyatakan tidak valid)

Nilai $r$ tebel dapat dilihat pada tabel $r$ statistik dengan $n=75$ atau $\mathrm{df}=\mathrm{n}-2=$ 73 dan dengan tingkat signifikansi 0,05 maka didapat nilai $r$ tabel $=0,2272$, sedang r hitung untuk Pendapatan Konsumen 0,710; Lokasi 0,754; Pelayanan 0,667; Selera 0,622; Kebersihan 0,542; Rekreasi/hiburan 0,612; Harga 0,669; Karena semua item memiliki $r$ hitung $>r$ tabel $(0,2272)$ maka semua item dinyatakan valid. 
2). Uji Reliabilitas.

Uji reliabilitas digunakan untuk mengetahui konsistensi alat ukur, apakah alat pengukur yang digunakan dapat diandalkan dan tetap konsisten jika pengukuranya tersebut diulang. Pengujian reliabilitas yang digunakan adalah dengan menggunakan metode Cronbach Alpha. Metode Cronbach Alpa digunakan untuk mencari nilai atau bentuk skala. Suatu variabel dikatakan reliabel jika memberikan nilai cronbach alpha $>0,60$ (Ghozali,2005).

Jadi dasar pengambilan keputusan untuk pengujian reliabilitas adalah sebagai berikut:

- Jika nilai Cronbach Alpa > 0,60 maka kuisioner yang diuji dinyatakan reliabel

- Jika nilai Cronbach Alpa $<0,60$ maka kuisioner yang diuji dinyatakan tidak reliabel .

Item-item yang tidak gugur pada uji validitas kemudian dimasukan pada uji reliabilitas. Setelah dihitung dengan bantuan program SPSS maka dapat diketahui nilai reliabilitas (cronbach's alpha) untuk masing-masing variabel berikut ini : Pendapatan konsumen 0,765; Lokasi 0,756; Pelayanan 0,772; Selera 0,784; Kebersihan 0,793; Rekreasi/hiburan 0,785; Harga 0,774. Karena nilai Cronbach untuk semua variabel di atas 0,60 , maka alat ukur tersebut reliabel atau telah memenuhi syarat reliabitas.

\section{HASIL ANALISIS DAN PEMBAHASAN}

\section{A. Analisis Kualitatif}

Analisa kualitatif ini digunakan untuk mengetahui karakteristik konsumen warung lesehan di Kota Yogyakarta, bedasarkan jenis kelamin, usia, pendidikan, pekerjaan, asal daerah.

Berdasarkan hasil kuisiner diperoleh karakteristik konsumen warung lesehan di Kota Yogyakarta sebagai berikut:

1). Karakteristik konsumen berdasarkan Jenis Kelamin, diketahui bahwa jumlah konsumen warung lesehan laki-laki sebanyak $40 \%$ dan konsumen warung lesehan permpuan sebanyak $60 \%$ hal ini menggambarkan bahwa konsumen 
warung lesehan perempuan lebih senang makan diwarung lesehan dibanding laki-laki.

2). Karakteristik konsumen berdasarkan umur, Konsumen warung lesehan terbanyak usia diatas antara 20 - 30 tahun sebanyak66 orang atau $44 \%$, disusul usia kurang dari 20 tahun sebanyak 30 atau 20\%, dan yang palin sedikit makan diwarung lesehan adalah konsumen dengan usia diatas 50 tahun sebanyak 14 atau 9,3\%. Hal ini sangat masuk akal karena di Kota Yogyakarta banyak pelajar dan mahasiswa yang indekos dengan rata-rata usia tersebut.

3). Karakteristik konsumen berdasarkan tingkat pendidikan, diketahui bahwa konsumen warung lesehan terbanyak adalah berpendidikan terakhir SLTA (mahasiswa) sebesar 72 konsumen atau 48\%, di urutan kedua berpendidikan perguruan tinggi sebanyak 38 atau $25,3 \%$, dan yang paling sedikit berpendidikan SD sebanyak 10 atau 6,7\%.

4). Karakteristik konsumen berdasarkan pekerjaan, jumlah konsumen terbanyak bekerja sebagai pelajar/mahasiswa ,kemudian disusul konsumen yang memiliki pekerjaanPNS sebesar 27,7\%, dan diikuti swasta/wiraswasta sebanyak $16 \%$. Sedangkan yang paling sedikit yang memiliki petani yaitu sebesar $4 \%$

5). Karakteristik konsumen berdasarkan asal daerah,diketahui bahwa jumlah konsumen warung lesehan menurut asal daerah adalah: konsumen yang berasal dari luar DIY sebanyak 69,3\% dan pengunjung yang berasal dari DIY sebanyak $30,7 \%$.

\section{B. Analisis Kuantitatif}

Analisis kuantitatif menggunakan analisis Chi-Square, analisis ini bertujuan untuk mengetahui variable dependen (Pendapatan, lokasi, pelayanan, selera, kebersihan, rekreasi/hiburan, harga) yang mempengaruhi perilaku konsumen warung lesehan di Kota Yogyakarta yang dicerminkan melalui tingkat keseringan melakukan pembelian di warung lesehan).Dari hasil perhitungan $\chi^{2}$ diperoleh hasil sebagaimana dalam tabel 4.1.berikut ini:

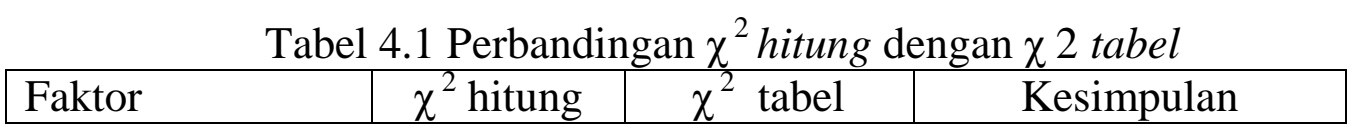




\begin{tabular}{|l|c|c|c|}
\hline Pendapatan & 28,227 & 16,919 & Ada hubungan \\
\hline Lokasi & 21,084 & 16,919 & Ada hubungan \\
\hline Pelayanan & 17,515 & 16,919 & Ada hubungan \\
\hline Selera & 24,386 & 16,919 & Ada hubungan \\
\hline Kebersihan & 18,329 & 16,919 & Ada hubungan \\
\hline Rekreasi/hiburan & 53,172 & 16,919 & Ada hubungan \\
\hline Harga & 26,104 & 16,919 & Ada hubungan \\
\hline
\end{tabular}

Sumber: Hasil perhitungan $\chi^{2 \text { hitung }}$ dan $\chi^{2}$ tabel

Berdasarkan analisis kuantitatif semua factor (pendapatan, lokasi, selera, kebersihan, rekreasi/hiburan dan harga) semua berpengaruh/ada hubungan terhadap perilaku konsumen warung lesehan di Kota Yogyakarta.Sedangkan untuk mengetahui faktor yang paling dominan mempengaruhi perilaku konsumen digunakan analisis coefficient of contingency dengan cara membandingan nilai coefficient of contingency (C) dengan nilai coefficient maksimum (C maks) sebagaimana tabel 4.2. berikut:

Tabel 4.2.Perbandingan Coefisien contingency (C) dengan Coefisien contingency maksimum (C maks)

\begin{tabular}{|l|c|c|c|c|}
\hline & C & C Maks & $\begin{array}{c}\text { Selisih C } \\
\text { dan C maks }\end{array}$ & Kesimpulan \\
\hline \multicolumn{1}{|c|}{ Faktor } & & & & \\
\hline Pendapatan & 0,398 & 0,866 & 0,468 & Hubungan lemah \\
\hline Lokasi & 0,351 & 0,866 & 0,515 & Hubungan lemah \\
\hline Pelayanan & 0,323 & 0,866 & 0,343 & Hubungan lemah \\
\hline Selera & 0,374 & 0,866 & 0,492 & Hubungan lemah \\
\hline Kebersihan & 0,330 & 0,866 & 0,536 & Hubungan lemah \\
\hline Rekreasi/hiburan & 0,512 & 0,866 & 0,354 & Hubungan kuat \\
\hline Harga & 0,385 & 0,866 & 0,481 & Hubungan lemah \\
\hline
\end{tabular}

Sumber: Hasil perhitungan $\mathrm{C}$ dan $\mathrm{C}$ maks

Faktor yang paling kuat pengaruhnya terhadap perilaku konsumen adalah rekreasi/hiburan, ini menunjukan bahwa warung lesehan dilihat tidak semata-mata tempat makan tetapi sudah menjadi arena/tempat menghibur diri/rekreasi bagi para konsumen. 


\section{KESIMPULAN DAN SARAN}

A. Kesimpulan

Dari hasil analisis faktor-faktor yang mempengaruhi perilaku konsumen warung lesehan di Kota Yogyakarta diperoleh kesimpulan sebagai berikut:

1. Berdasarkan karakteristik konsumen warung lesehan adalh sebagai berikut:

a. Berdasarkan jenis kelamin konsumen, jenis kelamin perempuan 90 resnponden atau $60 \%$ lebih banyak dibanding jenis kelamin laki-laki, yaiu sejumlah 60 responden atau $40 \%$.

b. Berdasarkan umur responden sebagian besar berumur 20 - 30 tahun yaitu sebanyak 66 responden atau 44\%, urutan kedua berumur kuran 20 tahun sebanyak 30 responden atau $20 \%$, sedang yang paling sedikit responden yang berumur lebih besar dari 50 tahun yaitu 14 orang atau 9,3\%.

c. Berdasarkan tingkat pendidikan, paling banyak berpendidikan SLTA yaitu 72 responden atau $48 \%$ kemudian Pendidikan Tinggi sebanyak 38 atau $25,3 \%$, sedangkan yang paling sedikit tidak sekolah/SD sebanyak 10 atau $6,7 \%$

d. Berdasarkan pekerjaan terbesar adalah pelajar/mahasiswa sebanyak 68 responden atau 45,3\%, disusul urutan ke dua PNS sebanyak 34 atau 22,7\% dan terkecil petani sebanyak 6 responden atau hanya $4 \%$.

e. Berdasarkan daerah asal, dari luar DIY sebanyak 104 atau 69,3\% sedangkan dari DIY sebanyak 46 atau 30,7\%.

2. Berdasarkan analisis kuantitatif semua factor (pendapatan, lokasi, selera, kebersihan, rekreasi/hiburan dan harga) semua berpengaruh/ada hubungan terhadap perilaku konsumen warung lesehan di Kota Yogyakarta.

3. Faktor yang paling kuat pengaruhnya terhadap perilaku konsumen adalah rekreasi/hiburan, ini menunjukan bahwa warung lesehan dilihat tidak sematamata tempat makan tetapi sudah menjadi arena/tempat menghibur diri/rekreasi bagi para konsumen.

B. Saran.

Berdasarkan kesimpulan diatas, saran yang dapat disampaikan adalah bahwa setiap pengelola warung lesehan sudah mulai harus berpikir bahwa, usaha warung lesehan tidak semata-mata menjual makanan dan minuman dengan harga yang 
murah tetapi harus sudah mulai bergeser dengan memikirkan bagaimana membuat konsumen itu nyaman dan terhibur sehingga selalu ingin datang ke warung lesehan dengan tujuan tidak hanya makan tetapi mencari hiburan/rekreasi

\section{DAFTAR PUSTAKA}

AA. Anwar Prabu Mangkunegoro, 1988, Perilaku Konsumen, Bandung PT ERESCO.

Anni Iwasaki, 2007, Yendaka Mengapa Orang jepang Ingin Pour ke Indonesia? Tingkat pelayanan kita," Suasana" (Juli).

Arikunto, Suharsimi, 2002, "Prosedur Penelitian: Suatau Pendekatan Prektek" Edisi Revisi V, Jakarta: PT Rineka Cipta

Basu Swasta DH dan T Hani Handoko, 2002, Manajemen Pemasaran: Analisis Perilaku Konsumen, BPFE Yogyakarta.

Chairul Hidayat, 1987, "Bisnis Goyang Lidah di Jakarta," Manajemen No. 50 Tahun VIII.

Djarwanto PS dan Pangestu Subagyo,2007,Statistik Induktif, BPFE, Yogyakarta.

Ghazali, Imam, 2005, Aplikasi Analilis Multivariat Dengan Menggunakan Program SPSS, Universitas Gajah Mada Press, Yogyakarta.

Kafi Kurnia, 1991, "Makan dan belanja”, Prospek, No 34 Tahun 1, (Juni).

Ki Mangun Atmojo, 1990, "Sepanjang Pengamen Sister Malioboro," Astek, (April-Mei).

Parlin, 1987, "Diam Sum, Santapan pagi Hongkong", Suasana No.03 (Juli).

Philip Kloter dan Keith Cox, 1984, "Manajemen dan Strategi Pemasaran", Erlangga, Jakarta. Penterjemah Taufiq Salim 